Azevedo, R.M.M.; Lopes, R.M.R.; Gonçalves, S. Ressignificação do rural e sua relação com o urbano: o turismo como expressão de novas possibilidades. Revista Brasileira de

Ecoturismo, São Paulo, v.6, n.5, nov-2013/jan-2014, pp.824-835.

\title{
Ressignificação do rural e sua relação com o urbano: o turismo como expressão de novas possibilidades
}

\author{
Reframing of the countryside and its relationship with the city: tourism \\ as an expression of new possibilities
}

\section{Raimunda Maria Marques de Azevedo, Rosa Maria Rodrigues Lopes, Salete Gonçalves}

\begin{abstract}
RESUMO
O presente estudo objetiva fazer uma discussão teórica acerca do turismo como uma expressão das novas possibilidades do espaço rural. Trata-se, nesse sentido, de uma abordagem direcionada para o turismo rural, modalidade que vem sendo desenvolvida no Brasil desde a segunda metade da década de 1980 e tem sido alvo de conturbados debates no tocante à sua caracterização conceitual. No decorrer do trabalho é proposto um diálogo entre os conceitos do rural, urbano e turismo, procurando mostrar os benefícios dessa atividade, tomando por base o desenvolvimento local. Sendo assim, trata-se de um estudo bibliográfico, baseado em uma revisão de literatura que aborda a temática do turismo rural em seus aspectos teóricos e conceituais. A partir das reflexões, constatou-se que o espaço rural vem se ressignificando, carregando consigo, múltiplas identidades que respaldam simbolismos modernos onde o valor cultural dado ao rural não é mais encerrado no atraso, na miséria, mas no natural, no bucólico, no saudável e no tradicional. E nesse sentido, o turismo se apropria do espaço rural dando a ele esse novo olhar direcionado o descanso, o prazer e o lazer, formatando mais um segmento. $O$ estudo destaca, também, a necessidade de se pensar e pôr em prática um turismo baseado em iniciativas endógenas, a partir da promoção do desenvolvimento local, consubstanciada em uma ação de interesse coletivo.
\end{abstract}

PALAVRAS-CHAVE: Relação Urbano-Rural; Turismo no Espaço Rural; Desenvolvimento Local.

\begin{abstract}
The present paper aims to make a theoretical discussion about tourism as an expression of new possibilities in rural space. It attends, in this sense, to an approach directed to rural tourism, modality that has been developed in Brazil since the second half of the 1980's and has been target of troubled debates regarding to its conceptual characterization. In the course of this paper it is proposed a dialogue between the concepts of rural, urban and tourism, trying to show the benefits of this activity, taking as basis local development. Thus, it's a bibliographical study, based in a literature review that broaches rural tourism's theme in its theoretical and conceptual aspects. From the reflections, it has been established that rural space comes reframing, carrying with itself, multiples identities that endorse modern symbolisms where the cultural value over the rural one is no longer enclosed in delay, misery, but in natural, bucolic, healthy and traditional. And in this sense, tourism appropriates of rural space giving it this new look directed to resting, pleasure and leisure, formatting a new segment. The study detaches also the need of thinking and putting into practice a tourism based in endogen initiatives, starting from the promotion of local development, consubstantiated in a common interest.
\end{abstract}

KEYWORDS: Relation Urban-Rural; Tourism in the Countryside; Local Development.

Página 824 Revista Brasileira de Ecoturismo, São Paulo, v.6, n.5, nov 2013-jan 2014, pp.824-835.

Sociedade Brasileira de Ecoturismo. Rua Dona Ana, 138, Vila Mariana, São Paulo, SP - Brasil. E-mail: rbecotur@sbecotur.org.br; Tel. (55-II) 99195-7685. 


\section{Introdução}

O texto que segue busca encaminhar uma discussão teórica com abordagem no turismo como expressão das novas possibilidades do espaço rural. Ao dar esse tratamento teórico, também se pretende discutir as relações urbano-rurais no contexto do processo de expansão do capital, haja vista, que é somente a partir dessa lógica que se vislumbram novos cenários, marcados por transformações econômicas diversas e contemporâneas que apresentam perspectivas inovadoras para os espaços rurais.

Nesse sentido, a discussão inicia-se com um aporte teórico relacionado ao rural em sua relação com 0 urbano, evidenciando a necessidade de leituras ancoradas em atividades plurais que dão aos espaços rurais uma nova formatação. Dessa forma, defende-se que o entendimento do que se compreende como urbano e rural deve pautar-se a partir de uma lógica relacional, refletida em substanciais mudanças no mundo rural, reestruturando-o em sentidos diversos, onde o turismo aparece fomentando novas possibilidades para esse espaço.

Com base nesses pressupostos teóricos e considerando a apropriação dos espaços rurais pela atividade turística, o texto prossegue com a abordagem teórica, localizando, do ponto de vista histórico, o início da atividade na Europa e especialmente no Brasil, além de contemplar sua localização geográfica e apresentar os acontecimentos que permitiram e promoveram as possibilidades de sua exploração, a exemplo dos ciclos econômicos vivenciados pelo país, deixando um importante legado histórico-cultural aproveitado, em muitas situações, pela prática do turismo rural.

Por fim, procurou-se discutir como essa atividade pode se configurar como instrumento de desenvolvimento local, a partir do aproveitamento de fatores endógenos às comunidades rurais, na perspectiva da autonomia coletiva, revelando, dessa forma, um grande desafio a ser superado pelas populações rurais.

\section{O rural em sua relação com o urbano: aportes teóricos}

O processo de urbanização do Brasil, condicionado pela lógica da integração territorial e da industrialização deu ao espaço urbano, à cidade expressão de relevo nos estudos acadêmicos em diversos campos do conhecimento, a exemplo da Geografia, da Sociologia e da Arquitetura. Essa lógica tem no comando, o sistema capitalista que apresenta como marca primeira a inserção de novos espaços geográficos, abarcando, por conseguinte espaços rurais que são modificados/ transformados através da impressão de novos significados e perspectivas, possibilitando, assim, outras leituras ancoradas em atividades plurais que dão aos espaços rurais uma reformatação.

Muitas vezes, essa nova formatação expressa a incorporação de tecnologias diferenciadas, marcada por novas relações de trabalho e de produção que se têm

Página 825 Revista Brasileira de Ecoturismo, São Paulo, v.6, n.5, nov 2013-jan 2014, pp.824-835. 
tornado comuns nas últimas décadas do século XX e primeiros anos do século XXI. É nessa vertente que se afirma o quanto os fatores socioeconômicos e políticos e suas consequentes repercussões espaciais, no sentido do processo de urbanização verificado no Brasil, redefiniram as relações rural-urbanas a partir de 1960. Dessa forma, de instâncias separadas, polarizadas e entendidas como opostas, cidade e campo passaram a ser compreendidos a partir de uma lógica relacional que tem na relação urbano-rural como ponto de partida.

Do ponto de vista de sua origem, a apreensão intelectual desses espaços têm se dado pelo entendimento da divisão social do trabalho, abarcando, por conseguinte, um amplo espaço de tempo que perpassa, de acordo com Rua (2006) pela derrocada do feudalismo na Europa e, mais recentemente pelo escravismo no Brasil que possibilitou a construção da hegemonia burguesa, deslocando o centro de poder do campo que tinha como expressão maior a agricultura para a cidade que passa a ter a indústria como característica representativa desse espaço.

Nesse contexto, para Lefebvre (2001, p. 28-29),

\begin{abstract}
A divisão social do trabalho entre a cidade e o campo corresponde à separação entre o trabalho material e o trabalho intelectual, e por conseguinte entre o natural e o espiritual. À cidade incumbe o trabalho intelectual: funções de organização e direção, atividades políticas e militares, elaboração do conhecimento teórico (filosofia e ciências) [...] O campo, ao mesmo tempo realidade prática e representação, vai trazer as imagens da natureza, do ser, do original. A cidade vai trazer as imagens do esforço, da vontade, da subjetividade, da reflexão, sem que essas representações se afastem de atividades reais. Dessas imagens confrontadas irão nascer grandes simbolismos.
\end{abstract}

Nesse ínterim faz-se mister apontar para o fato de que, mesmo com o surgimento da cidade como resposta à divisão social do trabalho, a sociedade urbana somente ganhou realce com a industrialização e o movimento de urbanização verificado muito tempo depois do surgimento das cidades da Antiguidade.

Isso posto, avançando na análise, o autor vai mostrar que a sociedade urbana tal como conhecemos é resultado do duplo processo de industrialização e de urbanização que teve início na Europa, por exemplo, a partir do século XVI. Esse momento é visto por Lefebvre (2001) como o ponto crítico das relações sociais no espaço urbano, pois elas se difundem, explodindo território afora, abarcando áreas rurais, como condição, meio e produto do processo de reprodução do capital e dos conflitos dessa reprodução e das necessidades da sociedade como um todo, tudo isso, dando maior complexidade à realidade urbana. A cidade, nessa análise, estaria relacionada à morfologia material, a um sentido prático-sensível, arquitetônico; e o urbano a uma morfologia social, uma realidade composta de relações particulares, mas interdependentes, em movimento, em constante transformação. 
Dessa forma, o conhecimento científico é chamado a atender o rural a partir de um sentido híbrido, prenhe de novos significados, possibilidades, perspectivas, valores, imbuído de uma constante dinamicidade, mesmo que permeado, ainda, e em muitos casos, por resistências que, contraditoriamente alimentam essa nova realidade, por intermédio de novas atividades no espaço rural, a exemplo do turismo e do agrobussiness.

Essas mudanças no modelo produtivo e organizacional do espaço rural sinalizam transformações importantes na sociedade brasileira, nas últimas décadas, evidenciando novas representações direcionadas ao rural que compõem um cenário construído por novas imagens e sentidos que reproduzem um produtivismo apoiado no modo capitalista de produção. Dessa forma, ao se tentar uma distinção entre rural e urbano, depara-se com uma conformação de forças que impulsionam o entendimento dessas categorias a partir de uma característica relacional.

Em sua dissertação que procura desmistificar o fim do rural, Blume (2004) destaca três abordagens importantes nas discussões acerca das relações ruralurbanas. A primeira delas corresponde à abordagem do novo rural brasileiro que se refere às contribuições dadas por estudos que têm no Professor José Graziano da Silva a sua referência; a segunda, trata o rural como uma categoria social realizada e que faz parte das discussões promovidas por Maria José Carneiro e Maria de Nazareth Baudel Wanderley; e a terceira abordagem, mais recentemente desenvolvida, relaciona-se ao enfoque territorial que tem sido bastante trabalhado pelo sociólogo José Eli da Veiga.

As três abordagens apresentam um ponto de conexão: reconhecem as novas dinâmicas nos espaços rurais e suas relações com os espaços urbanos. Todas estão direcionadas para a emergência de uma reconfiguração no meio rural que vem se processando no Brasil, algumas vezes de forma intensiva e outras, de forma bastante incipiente. $\mathrm{O}$ fato é que mudanças substanciais estão ocorrendo nessa área e o que diferencia as abordagens está nas diferentes interpretações extraídas desse processo de transformação.

É nessa perspectiva relacional que se busca pensar na complexidade que permeia as novas configurações rurais, pois a relação não amálgama as categorias: rural e urbano, mas justificam especificidades que são produtos da relação, ressignificando essas categorias de análise. Para Rua (2006), no espaço rural essa mudança acontece da seguinte forma,

[...] através da ideia de "urbanidades no rural" e inclui uma série de representações que reapresentam este espaço como um "outro rural". Este, concebido, primordialmente, na cidade, como uma nova mercadoria, comporta a face "natural" da natureza e porta uma virtualidade, que se torna real. Virtual e real se confundem nas recriações que as novas representações do rural carregam (2006, p. 95). 
Considerando, também, essas especificidades Wanderley (1996) defende que as mesmas são caracterizadas a partir das representações sociais com repercussão direta sobre as identidades, os direitos e as posições sociais dos indivíduos e grupos que compõem o campo e a cidade, particularizando essas espacialidades.

Nessa perspectiva, o turismo tem se apropriado desses valores para impulsionar sua reprodução, enquanto atividade econômica e prática social nos espaços rurais e configurando-se como novas possibilidades a ressignificar esses espaços.

\section{Turismo como uma expressão das novas possibilidades do espaço rural}

O turismo rural surge como mais um segmento no mercado turístico, que visa oferecer novas possibilidades de lazer em espaços que guardam importantes características naturais, com possibilidade de atividades tradicionais do campo. Tratase de uma prática recente no Brasil, quando comparada com o turismo de sol e mar. Esse teve sua origem na França, em 1971, e se apropriava de contrastes profundos no interior de países da Europa (SILVEIRA, 2003). Tais fatos deram surgimento, em 1972 a publicação de um Manifesto que contemplou no plano ecológico "a proteção do ambiente e a conservação do patrimônio histórico, arquitetônico e cultural' (SILVEIRA, 2003, p.135).

Estudos realizados por Almeida e Riedil (2000) apontam que o turismo rural, no âmbito da União Européia (UE) tem se configurado em um fator positivo no desenvolvimento de áreas rurais consideradas frágeis. $\mathrm{O}$ desenvolvimento do turismo rural, considerando os fatores positivos e o planejamento adequado, propicia o contato direto com o meio rural e a participação nas atividades, nos usos e nos costumes da população local, visando se organizar a partir de pequenas empresas e, nessas condições o ser humano se configura como elemento central e principal, sendo os costumes e a tradição considerados a essência da ruralidade.

Para Blos (2000), o turismo rural na Europa se constitui em um elemento capaz de criar oportunidades de novos negócios e promover a infraestrutura, já que se configura como um instrumento de intercâmbio entre o rural e o urbano. $O$ autor indica, ainda, à luz da experiência na Europa, que o turismo rural tem como uma das característica mais marcantes, além da capacidade de preservar as características do lugar, o equilíbrio entre os valores do passado, oferencendo o conforto da modernidade, a realidade de campo e as expectativas urbanas, sendo essas as características de maior relevância dessa prática que o autor indica.

No Brasil, segundo Rodrigues (2003) as primeiras iniciativas de Turismo Rural foram registradas no planalto catarinense, no município de Lages, no estado de Santa Catarina. Blos (2000) complementa que esse segmento turístico surgiu na década de 1980, motivado pela necessidade de gerar novas oportunidades de renda, já que esse período foi marcado por uma crise na agropecuária. 
Nesse sentido, o turismo rural veio contribuir com a valorização do lugar, da cultura local e como forma de agregar valor aos produtos. Blos (2000) aponta, também, que a parceria entre poder público e a iniciativa privada foi de destacada importância para o incremento da atividade, uma vez que o município de Lages conta com recursos naturais, tais como matas, rios, cascatas, clima ameno, além de fazendas centenárias, que fortalecem a identidade cultural e mantém viva a tradição do planalto catarinense, aliado à hospitalidade, a música, a dança, a culinária campeira e tradicional de imigrantes europeus.

A fazenda Pedras Brancas foi pioneira no projeto de turismo rural em Santa Catarina, porém, atualmente, existem várias fazendas integradas à atividade, destacando que, cada uma tem características peculiares, no entanto, atuando na pecuária, na criação de equinos, ovinos e aves, além de oferecer entretenimento aos turistas. Ressalta-se que essas fazendas são geralmente gerenciadas pelos proprietários e família, mas também contam com mão de obra contratada para atender a lida de campo e afazeres da fazenda, o que proporciona a geração de emprego e favorece a manutenção do homem no campo.

Rodrigues (2003) destaca que os principais elementos que motivam e favorecem a prática dessa atividade no Brasil é a grande extensão geográfica e as distintas fases do processo histórico, motivado pelos chamados ciclos econômicos que deixaram na paisagem aspectos marcantes, constituindo-se desse modo, um diversificado patrimônio histórico-cultural. Os ciclos mais representativos foram: o da cana-de-açúcar cujo cenário foi a zona da mata nordestina. Esse ciclo guardou um importante patrimônio arquitetônico, materializado nas casas de engenho e casa dos senhores. Outro importante ciclo econômico foi o do gado, que delimitou as fronteiras do Brasil de norte a sul e deixou como legado grandes rotas sendo que, parte dessas rotas hoje são utilizadas pelo turismo rural, através de roteiros integrados. O ciclo do café, na região sudeste do Brasil, deixou como importante legado cultural e material, propriedades senhoriais de relevante valor arquitetônico. Por fim, a era da mineração e das pedras preciosas que teve maior reflexo em áreas urbanas, muito embora favoreça a atividade de turismo rural em municípios do estado Minas Gerais, dado o patrimônio arquitetônico deixado como legado.

A autora ressalta ainda, que as iniciativas dessa modalidade de turismo se espalharam para todo o território nacional, com destaque para as regiões Sul e Sudeste do Brasil, e, mais recentemente, a região Centro-Oeste, com maior evidência para o estado de Mato Grosso do Sul. Com referência as regiões Norte e Nordeste, registram-se experiências pontuais de desenvolvimento de turismo rural (RODRIGUES, 2003).

Apesar da prática dessa atividade enquanto produto turístico registra-se divergências conceituais que acabam dificultando, sobremaneira, uma aproximação mais acurada em termos de conceitos. Assim, o que se observa no 
contexto nacional é um amálgama de definições, umas mais restritas ao tipo de atividade desenvolvida; outras mais amplas, mais solidárias em termos de práticas; e outras ainda mais complexas que abarcam o contexto, a prática e o cenário no qual são desenvolvidas. Tal variedade de atividades aponta para um cenário conceitual diverso a exemplo das seguintes denominações: Turismo Rural, Turismo Verde, Turismo Ecológico, Agroturismo, entre outros. Nesse contexto, é imperativo dizer que essas imprecisões se justificam pelo fato de muitas vezes tomarem como pressuposto o que já vem sendo discutido na Europa. Contudo, as modalidades se diferenciam dificultando, muitas vezes, uma afinidade de critérios que possam ser aplicados à realidade brasileira.

Na concepção de Rodrigues (2003, p. 102),

Ao atentarmos para a realidade brasileira o primeiro elemento de grande relevância é a artificial separação entre o mundo rural e o mundo urbano no período contemporâneo, cujos espaços, de maneira quase indiscriminada, são marcados por forte conteúdo de ciência, técnica e informação. Isso posto, os referenciais de classificação herdados da Idade Moderna, a partir do mercantilismo, já não servem, em razão das tênues diferenças entre aqueles espaços, salvo em territórios diametralmente opostos, caracterizados por excessiva urbanidade ou excessiva ruralidade.

Nessa questão a autora chama a atenção para um ponto importante que está relacionado ao próprio debate do que é urbano e rural na contemporaneidade. Para Sposito (2006), a discussão cidade-campo ganha ênfase se analisada do ponto de vista das descontinuidades territoriais, mostrando que a área de transição entre cidade e campo tem se ampliando, mostrando um nível maior de incongruências e dificultando, por conseguinte, a diferenciação entre espaços urbanos e rurais. Nesse sentido, essas formas espaciais são analisadas em superposição, constituindo um contínuo, cidade-campo. São, portanto, áreas de transição e contato entre esses espaços que se caracterizam por uma complementaridade entre ambos no mesmo território ou em "micro parcelas territoriais justapostas e sobrepostas, de usos do solo, de práticas socioespaciais e de interesses políticos associados ao mundo rural e ao mundo urbano" (SPOSITO, 2006. p. 121).

Esse é o sentido que se procurou resgatar, considerando que as descontinuidades territoriais permitem abordar as categorias cidade-campo, urbano-rural no campo das relações sociais, políticas e econômicas estabelecidas entre ambos. Segundo essa lógica, no decorrer do processo de urbanização, a unidade espacial urbana se refez em sua relação com o rural como resultado e condição das formas de produção territorial da cidade, no contexto do modo 
capitalista de produção, o que acabou por deixar imprecisos os limites entre esses dois espaços. Para a autora,

\begin{abstract}
Essa imprecisão cria, então, condições favoráveis a se pensar numa nova unidade espacial que contém, contraditoriamente, os dois espaços - o urbano e o rural - superpostos, amalgamados e intrinsecamente relacionados, razão pela qual são agora espaços urbanos/rurais (SPOSITO, 2006, p. 122).
\end{abstract}

A imprecisão acontece, por exemplo, quando há uma expansão territorial urbana por intermédio de loteamentos e implantação de equipamentos industriais, comerciais e de serviços. Entretanto, essa superposição se dá, também, para além do plano material, a partir da articulação entre esses espaços acontecendo pelo viés da expansão dos meios de comunicação que superam as morfologias cidade-campo em sua contradição. A temporalidade é outro aspecto que aproxima cidade e campo em razão da maior mobilidade dada entre esses espaços, estreitando relações sociais e culturais e ampliando a superposição entre eles.

Contudo, no que pese a necessidade de entender o espaço do ponto de vista dessas descontinuidades, chama-se a atenção para o fato de que alguns elementos rurais são relevantes no sentido da caracterização da atividade turística. Nesse sentido, Rodrigues (2003) aponta para o processo histórico de ocupação territorial, a estrutura fundiária, as características paisagísticas regionais, a estrutura agrária com destaque para as relações de trabalho, as atividades econômicas atuais, as características da demanda e os tipos de empreendimentos. Assim,

O turismo rural estaria correlacionado a atividades agrárias, passadas e presentes, que conferem à paisagem sua fisionomia nitidamente rural. Diferenciando-se, nesses casos das áreas cuja marca persistente é o seu grau de naturalidade, com ecossistemas ricos em biodiversidade, onde a natureza encontra-se ainda bastante preservada [...] (RODRIGUES, 2003, p. 103).

Com base no exposto, entendemos ser necessária a consideração desses elementos como forma até mesmo de diferenciar o turismo rural e o turismo em áreas rurais que pode ser um ecoturismo ou turismo de aventura. Assim, ressaltase que, o turismo rural deve abarcar os fatores expostos e se associar estritamente às atividades agrícolas e ao cotidiano rural de determinado espaço que, se associado a um modelo de exploração racional do patrimônio históricocultural e ambiental se tornaria um exemplo contundente de turismo com desenvolvimento local. 
A análise feita por Ávila et al. (apud MERIGUE, 2003) para o desenvolvimento local, permite ver um processo de base endógena, de origem local que revela a importância dada ao lugar, às potencialidades tanto do ponto de vista do território, enquanto substrato de poder, como dos agentes responsáveis pela construção do lugar, da identidade local. O que se quer destacar é que o desenvolvimento local só poderá ser entendido enquanto tal se for construído cotidianamente pelos atores sociais locais, em especial a população autóctone em parceria com agentes exógenos.

Para Ávila et al. (apud MERIGUE, 2003, p. 4),

O núcleo conceitual do desenvolvimento local consiste no efetivo desabrochamento - a partir do rompimento de amarras que prendam as pessoas em seus status quo de vida - das capacidades, competências e habilidades de uma comunidade definida (portanto com interesses comuns e situada em [...] espaço territorialmente delimitado, com identidade social e histórica), o sentido de ela mesma - mediante ativa colaboração de agentes externos e internos - incrementar a cultura da solidariedade em seu meio e tornar paulatinamente apta a agenciar (discernindo e assumindo dentre rumos alternativos de reorientação do seu presente e de sua evolução para o futuro aqueles que se the apresentem mais consentâneos) e gerenciar (diagnosticar, tomar decisões, agir, avaliar, controlar, etc.) o aproveitamento dos potenciais próprios - ou cabedais de potencialidades peculiares à localidade - assim como "metabolização" comunitária de insumos e investimentos públicos e privados externos, visando à processual busca de soluções para os problemas, necessidades e aspirações, de toda ordem e natureza, que mais direta e cotidianamente the dizem respeito.

Para a população local fica tão somente a perspectiva de participação no sentido do usufruto desse desenvolvimento. O discernimento, a autonomia para avaliar, qualificar e agir não existe, pois lhes faltam condições materiais e imateriais, o que limita as possibilidades de desenvolvimento local. Aos receptores resta a condição de espectadores do processo de transformação de seus lugares. O turismo de base local, ou comunitária, é então um desafio para essas e muitas localidades e realidade em poucas outras. Martins, 2002 apud Meringue (2003, p. 6) considera que:

O verdadeiro diferencial do desenvolvimento local não se encontra em seus objetivos (bem-estar, qualidade de vida, endogenia, sinergias, etc.), mas na postura que atribui e assegura à 
comunidade o papel de agente e não apenas beneficiária do desenvolvimento [...]. Implícita no conceito de desenvolvimento local está obviamente uma questão de escala territorial. Quando se fala de "local", está-se referindo à escala das inter-relações pessoais da vida cotidiana, que sobre uma base territorial constroem sua identidade.

Em relação às condições compensatórias do turismo com base local, Benevides (2002) considera que elas são extraídas de uma situação propícia de marginalidade que pode ser representada por espaços de comunidade tradicional, não mais primitiva e não autossuficiente; os espaços com base tradicional que apesar de apresentar alguma complexidade técnica, não se caracterizam plenamente capitalista, e os espaços com uma determinada preservação "natural", que está mais próximo do espaço natural do que do social.

O desenvolvimento proporcionado pela atividade turística surge então como resistência aos padrões dominantes, às barreiras de opressão da reprodução da vida e se enquadra em modalidades de turismo como ecológico, rural, alternativo, entre outros. Nesses termos, tem-se um desafio-problema, pois a condição de marginalidade configura uma situação limite ao desenvolvimento, uma vez que determinadas localidades se encontram enquadradas nas características de exclusão, não por escolha e sim por incapacidade, falta de autonomia de avaliar sua situação e propor no sentido de construir as bases de sua inclusão. Para Benevides (2002), o turismo como fator de desenvolvimento nessas comunidades, na abrangência em que o termo implica, deveria compatibilizar cinco objetivos, a saber: preservação/conservação ambiental, identidade cultural, geração de ocupações produtivas e de renda, desenvolvimento participativo e qualidade de vida.

\section{Considerações finais}

A partir das reflexões propostas constatou-se que o espaço rural vem se ressignificando e acabou por assumir múltiplas identidades que respaldam simbolismos modernos. Um desses simbolismos tem lugar na concepção de natureza que enquanto valor cultural dá ao rural outro significado, não mais encerrado no atraso, na miséria, mas no natural, no saudável, no tradicional.

Nesse contexto, a atividade turística vem despontando como uma alternativa viável ao desenvolvimento local dos espaços rurais, através de uma iniciativa endógena, consubstanciada de forma sólida como ação de interesse coletivo. No entanto, sabe-se que o desenvolvimento da atividade turística, numa perspectiva de desenvolvimento local só é possível mediante o conhecimento da história dos seus habitantes, da relação da população local com a natureza e das 
representações sociais dos grupos envolvidos e do respeito com seu modo de vida.

Vale ressaltar que essa atividade não deve ser vista como prioritária e exclusiva, acarretando numa perda de identidade local, e sim agregando valor aos modos de produção dos residentes locais. Neste cenário, faz-se necessário consolidar parcerias para um planejamento participativo do poder público municipal através de instituições detentoras de conhecimento e dispostas a trazer mais uma alternativa de desenvolvimento para as localidades rurais.

O texto busca, nesse sentido, provocar uma necessária reflexão e discussão teórica como forma de apontar caminhos de compreensão e transformação para se pensar e se provocar novas possibilidades no espaço rural, a partir da atividade turística.

\section{Referências bibliográficas}

ALMEIDA, J.A.; RIEDIL, M. (Org).Turismo Rural: ecología, lazer e desenvolvimento. Bauru: EDUSC, 2000.

BENEVIDES, I.P. Para uma agenda de discussão do turismo como fator de desenvolvimento local. In: RODRIGUES, A.B. (Org.) Turismo e desenvolvimento local. 3. ed. São Paulo: Hucitec, 2002. p. 23-41.

BLOS, W. O turismo rural na transição para um outro modelo de desenvolvimento rural. In: ALMEIDA. J.A.; RIEDL, M. Turismo rural: ecologia, lazer e desenvolvimento. Bauru: EDUSC, 2000. p. 199-222.

BLUME, R. Território e ruralidade: a desmistificação do fim do rural. Dissertação (mestrado). Universidade Federal do Rio Grande do Sul, Faculdade de Ciências Econômicas, Programa de Pós-Graduação em Desenvolvimento Rural, Porto Alegre, 2004.

LEFBVRE, H. O direito à cidade. São Paulo: Centauro, 2001.

MERIGUE, G.L. A gestão do turismo para o desenvolvimento local. 2003. Disponível em: http://www.etur.com.br. Acesso em: 04 abr 2010. 10p.

RODRIGUES, A.B. Turismo rural no Brasil: ensaio de uma tipologia. In: RODRIGUES, A.B. et al. (Orgs). Turismo rural: práticas e perspectivas. 2. Ed. São Paulo: Contexto, 2003. (Coleção Contexto). p.101-116.

RUA, J. Urbanidades no rural: o devir de novas territorialidades. Campo e território: Revista de Geografia Agrária, Uberlândia, v. 1, n. 1, p. 82-106, fev. 2006. 
SILVEIRA. M.A.T. Política de turismo: oportunidades ao desenvolvimento local. In: RODRIGUES. A.B. et al. (org). Turismo rural: práticas e perspectivas 2. ed. São Paulo, 2003. p.133-150.

SPOSITO, M.E.B. A questão cidade-campo: perspectivas a partir da cidade. In: SPOSITO, M.E.B.; WHITACKER, A.M. (Orgs.). Cidade e campo: relações e contradições entre urbano e rural. São Paulo: Editora Expressão Popular, 2006.

WANDERLEY, M.N.B. A ruralidade no Brasil moderno: por um pacto social pelo desenvolvimento rural. Anais do XX Encontro Anual da ANPOCS, Caxambu, 1996.

Raimunda Maria Marques de Azevedo: Universidade do Estado do Rio Grande do Norte, Natal, RN, Brasil.

E-Mail: azevedorai@yahoo.es

Link para o currículo Lattes: http://lattes.cnpq.br/9280823541520144

Rosa Maria Rodrigues Lopes: Universidade do Estado do Rio Grande do Norte, Natal, RN, Brasil.

E-Mail: rosamrlopes@gmail.com

Link para o currículo Lattes: http://lattes.cnpq.br/7794500005574533

Salete Gonçalves: Universidade do Estado do Rio Grande do Norte, Natal, RN, Brasil.

E-Mail: salleteg@yahoo.com.br

Link para o currículo Lattes: http://lattes.cnpq.br/9041519482141854

Data de submissão: 30 de maio de 2012

Data de recebimento de correções: 16 de julho de 2013

Data do aceite: 20 de setembro de 2013

Avaliado anonimamente 